\title{
Avaliação de diferentes propostas de restrição alimentar diurna para frangos de
}

\section{corte}

\author{
Evaluation of different changes in diurnal feed restriction for broilers \\ Evaluación de diferentes cambios en la restricción de alimentación diurna para pollos de engorde
}

Thiago de Sousa Melo

ORCID: https://orcid.org/0000-0003-1862-9571 Universidade Federal da Paraíba, Brasi E-mail: thiagosoumelo@hotmail.com

José Humberto Vilar da Silva

ORCID: https://orcid.org/0000-0001-8605-2829 Universidade Federal da Paraíba, Brasil E-mail: vilardasiva@yahoo.com.br

José Jordão Filho

ORCID: https://orcid.org/0000-0003-3964-9301 Universidade Federal da Paraíba, Brasil E-mail: jjordaofilho@yahoo.com.br

Fernando Guilherme Perazzo Costa ORCID: https://orcid.org/0000-0003-4075-1792 Universidade Federal da Paraíba, Brasil E-mail: perazzo63@gmail.com

Patrícia Emília Naves Givisiez

ORCID: https://orcid.org/0000-0002-2480-1780 Universidade Federal da Paraíba, Brasil E-mail: patricia@cca.ufpb.br

Flávio Bruno Soares de Lima

ORCID: https://orcid.org/0000-0002-9853-4232 Universidade Federal da Paraíba, Brasil E-mail: flaviobruno17@hotmail.com

Aliton Nunes da Silva

ORCID: https://orcid.org/0000-0002-1089-8454 Universidade Federal da Paraíba, Brasil

E-mail: aliton_nunes@hotmail.com

Silvana Cristina de Lima dos Santos

ORCID: https://orcid.org/0000-0003-4899-9514 Universidade Federal do Rio Grande do Norte, Brasil E-mail: silvanalimazoo@hotmail.com

Mário Cesar de Lima

ORCID: https://orcid.org/0000-0002-5226-3094 Universidade Federal da Paraíba, Brasil E-mail: mariocesarufpb@gmail.com

Leandro de Araújo

ORCID: https://orcid.org/0000-0001-8744-9027 Universidade Federal da Paraíba, Brasil

E-mail: leoaraujog@hotmail.com

\begin{abstract}
Resumo
Os programas de restrição alimentar surgem na indústria avícola como alternativa de melhorar as taxas de índices zootécnicos. Com isso, objetivou-se avaliar o efeito das propostas de restrição alimentar de curta duração sobre o desempenho de frangos de corte. Um total de 1.260 frangos de corte foram distribuídos em delineamento inteiramente ao acaso, em quatro programas de alimentação (PA) com nove repetições de 35 aves. Os PA avaliados foram: $\mathrm{P}_{1}=a d$ libitum ( $\mathrm{AL})$; suspensão da oferta diária da ração de: 06:00 às 08:00 h da manhã $(\mathrm{RM})\left(\mathrm{P}_{2}\right)$; de 13:00 às 15:00 h da tarde (RT) $\left(\mathrm{P}_{3}\right)$ e $\mathrm{P}_{4}$ de 06:00 às 08:00 h da manhã e de 13:00 as 15:00 h da tarde (RMT). Não houve diferença estatística no peso corporal aos 21, 35 e 42 dias, consumo de ração, conversão alimentar, características de carcaça, medidas físicas e a resistência à quebra do fêmur e da tíbia e o índice Seedor do fêmur. Quanto ao ganho de peso do grupo RMT foi maior em dois períodos de avaliação ( 35 e 42 d) em relação ao grupo AL. O índice glicêmico dos frangos sob restrição alimentar foi menor em relação ao AL. A RT reduziu o peso da gordura abdominal e das penas. O índice Seedor da tíbia do grupo AL foi menor em relação aos tratamentos com RT e RMT. O programa restrição alimentar quantitativo de 4 horas (RMT) melhora o desempenho, qualidade óssea e econômica nos frangos de corte de 8 aos $42 \mathrm{~d}$ de idade.
\end{abstract}

Palavras-chave: Glicose; Índice de eficiência econômica; Realimentação; Resistência óssea. 


\begin{abstract}
Feed restriction programs arose in the poultry industry as an alternative to improve zootechnical index rates. Thus, this study aimed to evaluate the effect of short-term feed restrictions on the performance of broilers. For this, 1,260 male were distributed in a completely randomized design in four feeding programs (FP), with nine replicates of 35 broilers each. The following FP were: $\mathrm{P}_{1}=$ ad libitum $(\mathrm{AL})$; suspension of the daily feed supply, from 06:00 to 08:00 in the morning $(\mathrm{RM})\left(\mathrm{P}_{2}\right)$, from 01:00 to 03:00 in the afternoon (RA) $\left(\mathrm{P}_{3}\right)$ and $\mathrm{P}_{4}=06: 00$ to 08:00, in the morning, and from 01:00 to 03:00, in the afternoon (RMA). There was no statistical difference in body weight at 21, 35, and 42 days, feed intake, feed conversion, carcass characteristics, physical measurements, femur and tibia fracture resistance, and the femur Seedor index. The weight gain in the RMA group was higher in two evaluation periods (35 and $42 \mathrm{~d}$ ) in comparison with the AL group. The glycemic index was lower in broilers subjected to feed restriction than in those subjected to AL. The RA reduced the weight of abdominal fat and feathers. The tibia Seedor index in the AL group was lower than those in the RA and RMA groups. The quantitative feed restriction program for 4 hours improves performance and bone and economic quality in broilers, from 8 to 42 days old.
\end{abstract}

Keywords: Bone strength; Glucose; Economic efficiency index; Refeeding.

\title{
Resumen
}

Los programas de restricción alimentaria surgieron en la industria avícola como una alternativa para mejorar las tasas de los índices zootécnicos. Por lo tanto, este estudio tuvo como objetivo evaluar el efecto de las restricciones alimentarias a corto plazo sobre el rendimiento de pollos de engorde. Para ello, se distribuyeron 1.260 machos en un diseño completamente al azar en cuatro programas de alimentación (PA), con nueve réplicas de 35 pollos de engorde cada una. Se evaluaron los siguientes $\mathrm{PA}: \mathrm{P}_{1}=$ ad libitum (AL); suspensión del aporte diario de pienso, de las 06:00 a las 08:00 de la mañana $(\mathrm{RM})\left(\mathrm{P}_{2}\right)$, de la 1:00 a las 3:00 de la tarde $(\mathrm{RT})\left(\mathrm{P}_{3}\right)$ y $\mathrm{P}_{4}=$ de las 06:00 a las 08: 00 de la mañana y de la 1:00 a las 3:00 de la tarde (RMT). No hubo diferencia estadística en el peso corporal a los 21, 35 y 42 días, consumo de alimento, conversión alimenticia, características de la canal, medidas físicas, resistencia a la fractura de fémur y tibia, ni en el índice de Seedor del fémur. El aumento de peso en el grupo RMT fue mayor en dos períodos de evaluación ( 35 y 42 d) en comparación con el grupo AL. El índice glucémico fue menor en los pollos de engorde sometidos a la restricción alimentaria que en los sometidos a AL. La RT redujo el peso de la grasa abdominal y de las plumas. El índice de Seedor de la tibia en el grupo AL fue más bajo que en los grupos RT y RMT. El programa de restricción cuantitativa de alimento durante 4 horas mejora el rendimiento y la calidad ósea y económica en pollos de engorde, de los 8 a los 42 días de edad.

Palabras clave: Fuerza ósea; Glucosa; Índice de eficiencia económica; Realimentación.

\section{Introduçãa}

A cadeia produtiva dos frangos demanda estratégias inovadoras que estimulem o desempenho das aves, acompanhado da máxima produção de carne magra com menor custo de produção, baixa mortalidade e de incidência de distúrbios metabólicos que interferem no bem-estar das aves. Portanto, o desenvolvimento de métodos de restrição alimentar pode ser uma alternativa para máxima produção de carne com melhor eficiência econômica. De acordo com Duarte et al. (2012), os rendimentos de carcaça, peito, coxa e sobrecoxa podem ser diretamente influenciados pela dieta e pelos programas alimentares.

A restrição alimentar é uma prática de manejo que tem por objetivo reduzir o consumo de ração e o custo de alimentação por um determinado período, sem afetar a taxa de ganho de peso (Rosa et al., 2000). Esta prática promove o ganho compensatório em aves (Novel et al., 2009) e resulta numa maior eficiência de utilização dos nutrientes.

O método de restrição alimentar melhora a conversão alimentar (Tolkamp et al., 2005; Zhan et al., 2007), reduz a incidência de doenças metabólicas e a deposição de gordura na carcaça de frangos de corte (Yu \& Robinson, 1992), considerando que a oferta ad libitum de ração aumenta a taxa de crescimento, mas também, aumenta a incidência de distúrbios metabólicos como a ascite, síndrome da morte súbita e problemas esqueléticos (Yu \& Robinson, 1992).

O rápido crescimento é acompanhado pelo aumento de anormalidades no tecido esquelético em frangos, principalmente dos ossos longos como fêmur e tíbia (Sullivan, 1994). A atenuação da ocorrência destes problemas é de interesse de produtores e de consumidores por envolver o bem-estar animal e elevadas perdas econômicas (Araújo et al., 2011). Ainda não existe uma padronização de práticas de aplicação dos métodos de restrição alimentar, sendo mais utilizados a restrição por tempo (Saber et al., 2011), pela suspensão do programa de luz (Religious et al., 2001), pela diluição da dieta (Zubair \& Lesson, 1996), e pelos 
métodos químicos e quantitativos (Zhan et al., 2007; Saber et al., 2011) com resultados controversos.

Considerando os resultados inconsistentes entre os diferentes programas de restrição alimentar em frangos de corte este trabalho foi realizado com o objetivo de avaliar o efeito de novas propostas de restrição alimentar de curta duração sobre o desempenho de frangos de corte.

\section{Metodologia}

O experimento foi conduzido no aviário do Laboratório de Avicultura do Departamento de Ciência Animal do Centro de Ciências Humanas Sociais e Agrárias, da Universidade Federal da Paraíba, Campus III, no município de Bananeiras, sob as coordenadas $6^{\circ} 45^{\prime} 00^{\prime \prime}$ de latitude sul e $35^{\circ} 38^{\prime} 00^{\prime \prime}$ de longitude oeste, a uma altitude de $520 \mathrm{~m}$ acima do nível do mar, no período de 05 de março a 09 de abril de 2016.

Foram distribuídos 1.260 pintos de corte, macho da linhagem Cobb 500 "Slow Feathering" ${ }^{\circledR}$, no período de oito a 42 dias de idade com peso vivo médio de $185 \pm 2 \mathrm{~g}$, em delineamento inteiramente casualizado, pesados e distribuídos em quatro tratamentos experimentais, com nove repetições de 35 aves. Os quatros programas alimentares foram os seguintes: Programa 1 - Alimentação ad libitum durante todo o período experimental (AL); Programa 2 - Suspenção da oferta diária de ração nos intervalos de 06:00 às 08:00 h da manhã (RM); Programa 3 - Suspenção da oferta diária de ração nos intervalos de 13:00 às 15:00 h da tarde (RT); Programa 4 - Suspenção da oferta diária de ração nos intervalos de 06:00 às 08:00 h da manhã e das 13:00 às 15:00 $\mathrm{h}$ da tarde (RMT).

A dieta basal (Tabela 1) foi formulada para atender as exigências dos frangos para crescimento normal segundo Rostagno et al. (2011). Antes do período de restrição alimentar, as aves receberam água e ração ad libitum e o manejo foi realizado de acordo com o Manual da Linhagem Cobb (2012).

Aos oito dias de idade, as aves foram transferidas para os 36 boxes medindo 2,00 x 1,70 m (3,4 $\left.\mathrm{m}^{2}\right)$ com paredes divisórias em tela com abertura de malha à prova de pássaros e piso coberto com cama de maravalha. Cada box foi equipado com um comedouro tubular e um bebedouro pendular. A área experimental está instalada num galpão de alvenaria com cortinas laterais, ventiladores e nebulizadores, utilizados para ajustar a temperatura e umidade relativa do ar.

Foi adotado um programa de luz contínuo durante todo o período experimental, utilizando-se lâmpadas incandescentes de 100 watts de forma a fornecer 22 lúmens $/ \mathrm{m}^{2}$. Um termohigrômetro digital foi utilizado para aferição e registro da temperatura e umidade relativa do ar de oito horas da manhã e 15 horas da tarde que foram, respectivamente, de $29,9 \pm 2,2{ }^{\circ} \mathrm{C}$ e $68,6 \pm 6,7 \%$.

Ao final do período experimental, as sobras de rações e os frangos foram pesados, para avaliação do consumo de ração, ganho de peso e conversão alimentar. O consumo de ração foi obtido pela diferença entre a ração fornecida e as sobras, o ganho de peso foi calculado pela diferença entre o peso dos frangos no final e inicial; enquanto que, a conversão alimentar foi calculada pela divisão do consumo de ração pelo ganho de peso.

Aos 42 dias de idade, um total de 72 animais, sendo dois por parcela e 18 por tratamento foram selecionados com base no peso médio e submetido a jejum de sólidos de oito horas a fim de limpar o trato digestivo. Após o jejum, as aves foram pesadas individualmente, insensibilizadas por eletronarcose e, posteriormente, sacrificadas e evisceradas para obtenção do peso da carcaça, dos cortes nobres (peito, coxa, sobrecoxa e asas), órgãos comestíveis e da gordura abdominal. 
Tabela 1. Composição percentual das dietas experimentais ${ }^{1}$ para frangos de corte nas fases inicial (8 a 21 dias), crescimento ( 22 a 35 dias) e final (36 a 42 dias).

\begin{tabular}{|c|c|c|c|c|}
\hline \multirow{2}{*}{ Ingredientes } & & \multicolumn{3}{|c|}{ Quantidade (Kg) } \\
\hline & & Inicial & Crescimento & Final \\
\hline Milho em grão & & 56,984 & 59,970 & 64,214 \\
\hline Farelo de soja & & 35,976 & 32,397 & 28,534 \\
\hline Óleo de soja & & 3,259 & 4,179 & 4,105 \\
\hline Fosfato bicálcico & & 1,555 & 1,334 & 1,123 \\
\hline Calcário calcítico & & 0,934 & 0,879 & 0,787 \\
\hline DL-metionina & & 0,307 & 0,289 & 0,268 \\
\hline L-lisina HCL & & 0,235 & 0,235 & 0,261 \\
\hline L-treonina & & 0,073 & 0,065 & 0,069 \\
\hline Sal comum & & 0,482 & 0,457 & 0,445 \\
\hline Cloreto de colina & & 0,060 & 0,060 & 0,060 \\
\hline Premix vitamínico ${ }^{2}$ & & 0,050 & 0,050 & 0,050 \\
\hline Premix mineral $^{3}$ & & 0,050 & 0,050 & 0,050 \\
\hline $\mathrm{BMD}^{4}$ & & 0,015 & 0,015 & 0,015 \\
\hline Anticoccidiano $^{5}$ & & 0,010 & 0,010 & 0,010 \\
\hline Antioxidante 6 & & 0,010 & 0,010 & 0,010 \\
\hline Total & & 100,000 & 100,000 & 100,000 \\
\hline Composição Nutricional & Unidade & & & \\
\hline Proteína Bruta & $\%$ & 21,200 & 19,800 & 18,400 \\
\hline EMAn (Mcal/kg) & $\mathrm{Mcal} / \mathrm{kg}$ & 3.050 & 3.150 & 3.200 \\
\hline Lisina digestível & $\%$ & 1,217 & 1,131 & 1,060 \\
\hline Metionina digestível & $\%$ & 0,588 & 0,554 & 0,519 \\
\hline Met+Cis digestível & $\%$ & 0,876 & 0,826 & 0,774 \\
\hline Treonina digestível & $\%$ & 0,791 & 0,735 & 0,689 \\
\hline Triptofano digestível & $\%$ & 0,237 & 0,218 & 0,198 \\
\hline Cálcio & $\%$ & 0,841 & 0,758 & 0,663 \\
\hline Fósforo disponível & $\%$ & 0,401 & 0,354 & 0,309 \\
\hline Sódio & $\%$ & 0,210 & 0,200 & 0,195 \\
\hline Potássio & $\%$ & 0,824 & 0,767 & 0,708 \\
\hline Cloro & $\%$ & 0,394 & 0,379 & 0,378 \\
\hline Balanço Eletrolito & $\mathrm{mEq} / \mathrm{kg}$ & 191 & 176 & 159 \\
\hline
\end{tabular}

${ }^{1}$ Recomendações nutricionais de Rostagno et al. (2011);

${ }^{2}$ Níveis de garantia por kg do produto: Vitamina A 6.800.000 UI; vitamina D3 1.500.000 UI; vitamina E 12.000 UI; vitamina K3 1.600 mg; vitaminas B1 $1.000 \mathrm{mg}$; vitamina B2 $4.000 \mathrm{mg}$; vitamina B6 $2.000 \mathrm{mg}$; vitamina B12 $10.000 \mathrm{mg}$; ácido fólico 700 mg; ácido pantotênico 10 g; biotina $15 \mathrm{mg}$; niacina $30 \mathrm{~g}$; BHT $1.000 \mathrm{mg}$. 3Níveis de garantia por kg do produto: Cobre $20 \mathrm{~g}$; ferro $96 \mathrm{~g}$; iodo $1.400 \mathrm{mg}$; manganês 156 $\mathrm{g}$; selênio $500 \mathrm{mg}$; zinco $110 \mathrm{~g}$;

${ }^{4}$ Bacitracina metileno disalicilato;

${ }^{5} \operatorname{Coxistac}^{\circledR}$ (Salinomicina) - 12\% granular;

${ }^{6}$ Santoquim ${ }^{\circledR}$.

Fonte: Elaborada pelos autores.

Na determinação do rendimento de carcaça foi considerado o peso da carcaça limpa e eviscerada, sem cabeça, pernas e pés em relação ao peso vivo após jejum, enquanto, os rendimentos dos cortes (peito, coxa, sobrecoxa e asas) e dos órgãos comestíveis (moela, fígado e coração) foram calculados dividindo-se o peso individual de cada corte e/ou órgão pelo peso da carcaça.

A determinação da glicemia dos frangos foi realizada aos 42 dias de idade, em amostras de sangue de duas aves por unidade experimental, totalizando 18 animais por tratamento. As amostras de sangue das aves de todos os tratamentos foram colhidas, após puntura da crista com agulha, em tiras do kit teste Monitor de Glicemia Contour ${ }^{\circledR}$ Ts Bayer. Nas aves em regime de restrição alimentar as amostras de sangue foram colhidas em intervalos de duas horas antes, durante e depois da restrição alimentar, 05h50min; 07h50min e 09h50min, respectivamente.

Aos 42 dias de idade, um total de 36 animais, sendo um por parcela e nove por tratamento foram selecionados, 
sacrificado e depois retirados os ossos dos fêmures e das tíbias, direita e esquerda, sendo identificadas e em seguida congeladas a $-20^{\circ} \mathrm{C}$ para a realização das análises posteriores. A tíbia e o fêmur foram os ossos escolhidos por serem os mais longos e mais sujeito a rupturas (estresse motor) do esqueleto, além de serem retirados com maior facilidade. Para a realização da desossa, os fêmures e tíbias foram descongelados em geladeira à $4{ }^{\circ} \mathrm{C}$ por 24 horas. Em seguida, foram pesados, identificados e mergulhados em água fervente por aproximadamente 10 minutos. As desossas foram realizadas com auxílio de um bisturi.

As pesagens dos fêmures e tíbias foram realizadas utilizando uma balança eletrônica com precisão de ( $\mathrm{g} \pm 0,001)$ da marca GEHAKA - Modelo AG-200, e as medições do comprimento $(1 \mathrm{~mm} \pm 0,01)$ do osso e o diâmetro da epífise proximal e distal, bem como da diáfise dos respectivos tratamentos foram feitas com o auxílio de um paquímetro digital da marca Digimess, com precisão de $1 \mathrm{~mm} \pm 0,01$. Após as análises físicas dos ossos, os mesmos valores de comprimento e pesos do fêmur e da tíbia foram usadas para determinar a densidade óssea $(\mathrm{mg} / \mathrm{mm}$ ) pelo método indireto de índice Seedor (Seedor, 1991) onde: $\mathrm{IS}=$ peso do osso $\div$ comprimento do osso.

Após a determinação do índice Seedor, as tíbias foram submetidas à análise de resistência à quebra $\left(\mathrm{kgf} / \mathrm{cm}^{2}\right)$ no aparelho universal de teste TA.XT Plus (Texture Analyzer Stable Micro Systems, Surrey, UK) com célula de carga de $50 \mathrm{~kg}$ a velocidade de $50 \mathrm{~mm} / \mathrm{min}$, o acessório para fratura 3 POINT BEND RIG (HDP/3PB), Stable Micro Systems, foi regulado para permitir que o vão livre da diáfise fosse de 3,0 cm (Park et al., 2003).

A viabilidade econômica das rações foi avaliada considerando o impacto financeiro da restrição alimentar nas fases de criação sobre as variáveis de desempenho e rendimento de carcaça. Os índices econômicos foram calculados conforme metodologia descrita por Ramos et al. (2011) considerando: o Custo Médio da Ração (CMR) = ração consumida x preço de ração; Receita Média Bruta $(\mathrm{RMB})$ = quantidade de quilograma de frango produzida $\mathrm{x}$ preço do frango vivo; Margem Bruta $(\mathrm{MB})=$ receita média bruta - custo médio da ração; Índice de Rentabilidade $(\mathrm{IR})=$ margem bruta $\div$ custo médio da ração e Índice Relativo de Rentabilidade $($ IRR $)=$ renda média do tratamento testado $\div$ renda média do tratamento controle x 100. Além disso, foi calculado o índice de eficiência produtiva (IEP) de acordo com Gomes et al. (1996) que foi expresso pela seguinte equação: $\mathrm{IEP}=[($ peso vivo médio das aves $(\mathrm{g}) \mathrm{x}$ viabilidade das aves $(\%)) \div($ idade das aves (dias) x conversão alimentar (g/g) $)]$ x 100 . Os preços dos ingredientes utilizados para elaboração da análise econômica foram provenientes de consulta ao mercado paraibano, assim como, o preço do frango vivo, enquanto que os aminoácidos foram obtidos de empresas fornecedoras, considerando a cotação do dólar.

Os dados colhidos ao final de cada fase foram tabulados para posterior análise estatística utilizando-se o programa computacional Software "Statistical Analysis System" (SAS, 2009). Os dados referentes ao desempenho e rendimento de carcaça foram analisados pelo teste Tukey e os dados de qualidade óssea pelo teste Duncan em nível 5\% de probabilidade. O modelo estatístico foi o seguinte: $Y_{i j}=\mu+t_{i}+e_{i j}$, em que: $Y_{i j}=$ é a $i$-ésima observação referente a $j$-ésima repetição, $j=1,2, \ldots, J(\mathrm{~J}=$ 9); $\mu$ = média geral; $t_{i}=$ efeito do $i$-ésimo tratamento, $i=1,2, \ldots, I(\mathrm{I}=4) ; e_{i j}=$ erro experimental suposto homocedástico, independente e normalmente distribuído. Os dados percentuais de mortalidade $(\mathrm{x})$ foram transformados em $(\mathrm{x}+0,50)^{0,5}$ antes da ANOVA para homogeneização da variância e normalização dos dados, segundo Bartlett (1947).

\section{Resultados e Discussão}

\section{Desempenho}

O consumo de ração, o peso corporal e a conversão alimentar não foram influenciados pelos programas de alimentação ( $\mathrm{P}>0,05)$, porém o ganho de peso de 8 a 35 dias $(\mathrm{p} \leq 0,05)$ e novamente o ganho de peso de 8 a 42 dias $(\mathrm{p} \leq 0,05)$ foram afetados pelos os programas de alimentação (Tabela 2). 
Tabela 2. Efeito de diferentes programas de alimentação sobre o desempenho de frangos de corte de acordo com o período de avaliação

\begin{tabular}{|c|c|c|c|c|c|c|c|}
\hline \multirow{3}{*}{ Período } & \multicolumn{4}{|c|}{ Programas de alimentação ${ }^{1}$} & \multirow{3}{*}{ EPM } & \multirow{3}{*}{ Valor de P } & \multirow{3}{*}{$\mathrm{CV}(\%)$} \\
\hline & \multirow{2}{*}{ Ad libitum } & \multicolumn{3}{|c|}{ Tempo de restrição à ração } & & & \\
\hline & & $2 \mathrm{~h}(\mathrm{M})$ & $2 \mathrm{~h}(\mathrm{~T})$ & $4 \mathrm{~h}(\mathrm{MT})$ & & & \\
\hline \multicolumn{8}{|c|}{ Consumo de Ração (g) } \\
\hline $8-21 \mathrm{~d}$ & $1.167,84 \pm 21$ & $1.165,63 \pm 21$ & $1.167,18 \pm 23$ & $1.152,45 \pm 35$ & 4,24 & 0,5495 & 2,22 \\
\hline $8-35 \mathrm{~d}$ & $3.273,87 \pm 48$ & $3.315,80 \pm 40$ & $3.272,23 \pm 60$ & $3.310,29 \pm 41$ & 8,34 & 0,1172 & 1,45 \\
\hline $8-42 \mathrm{~d}$ & $4.341,71 \pm 92$ & $4.382,46 \pm 65$ & $4.315,92 \pm 90$ & $4.398,90 \pm 79$ & 13,76 & 0,1251 & 1,81 \\
\hline \multicolumn{8}{|c|}{ Peso Corporal (g) } \\
\hline $21 \mathrm{~d}$ & $1.088,42 \pm 12$ & $1.085,60 \pm 22$ & $1.086,08 \pm 9$ & $1.084,71 \pm 7$ & 2,21 & 0,9488 & 1,27 \\
\hline $35 \mathrm{~d}$ & $2.361,55 \pm 60$ & $2.385,05 \pm 40$ & $2.374,75 \pm 44$ & $2.405,42 \pm 56$ & 8,48 & 0,3206 & 2,12 \\
\hline $42 \mathrm{~d}$ & $2.921,83 \pm 64$ & $2.921,19 \pm 85$ & $2.914,35 \pm 55$ & $2.939,89 \pm 104$ & 12,77 & 0,9161 & 2,72 \\
\hline \multicolumn{8}{|c|}{ Ganho de Peso (g) } \\
\hline $8-21 \mathrm{~d}$ & $872,75 \pm 17$ & $874,90 \pm 14$ & $884,60 \pm 12$ & $873,85 \pm 37$ & 3,67 & 0,6646 & 2,56 \\
\hline $8-35 d$ & $2.126,92 \pm 50^{\mathrm{B}}$ & $2.178,68 \pm 29^{A}$ & $2.164,87 \pm 44^{\mathrm{AB}}$ & $2.188,64 \pm 41^{\mathrm{A}}$ & 7,75 & 0,0201 & 1,93 \\
\hline $8-42 \mathrm{~d}$ & $2.674,96 \pm 55^{\text {B }}$ & $2.725,07 \pm 47^{\mathrm{AB}}$ & $2.711,50 \pm 47^{\mathrm{AB}}$ & $2.750,96 \pm 56^{\mathrm{A}}$ & 9,50 & 0,0317 & 1,92 \\
\hline \multicolumn{8}{|c|}{ Conversão Alimentar (g/g) } \\
\hline $8-21 \mathrm{~d}$ & $1,338 \pm 0,02$ & $1,333 \pm 0,03$ & $1,319 \pm 0,02$ & $1,320 \pm 0,04$ & 0,005 & 0,3531 & 2,05 \\
\hline $8-35 \mathrm{~d}$ & $1,540 \pm 0,03$ & $1,522 \pm 0,01$ & $1,512 \pm 0,02$ & $1,513 \pm 0,02$ & 0,004 & 0,0459 & 1,25 \\
\hline $8-42 \mathrm{~d}$ & $1,623 \pm 0,03$ & $1,608 \pm 0,02$ & $1,603 \pm 0,02$ & $1,599 \pm 0,02$ & 0,004 & 0,1379 & 1,42 \\
\hline
\end{tabular}

A,BMédias seguidas de letras maiúsculas distintas na linha diferem entre si pelo teste de Tukey $(\mathrm{P}>0,05)$;

${ }^{1}$ Programa $1\left(\mathrm{P}_{1}\right)$ : Alimentação ad libitum durante todo o período experimental $(\mathrm{AL})$; $\mathrm{P}_{2}$ : Suspenção da oferta de ração nos intervalos de 06:00 às 08:00 h da manhã $(\mathrm{RM}) ; \mathrm{P}_{3}$ : Suspenção da oferta de ração nos intervalos de 13:00 às 15:00 h da tarde (RT) e; $\mathrm{P}_{4}$ : Suspenção da oferta de ração nos intervalos de 06:00 às 08:00 h da manhã e de 13:00 às 15:00 h da tarde (RMT);

EPM = erro-padrão da média; $\mathrm{CV}=$ coeficiente de variação.

Fonte: Elaborada pelos autores.

A falta do efeito do consumo de ração dos frangos sob restrição alimentar foi em função da curta duração na metodologia de suspenção de ração que varia de duas a quatros horas em relação ao grupo ad libitum. Este resultado discorda daqueles de Sahraei \& Shariatmadari (2007) que encontraram maior consumo de ração para os frangos submetidos a restrição alimentar. Segundo Guyton \& Hall (1997), quando a disponibilidade dos nutrientes diminui, o animal automaticamente aumenta a ingestão de alimento provocada pelos estímulos do centro da fome no hipotálamo lateral.

Os frangos submetidos a restrição alimentar de 4 horas (MT) e 2 horas (manhã) apresentaram maior ganho de peso $(\mathrm{p} \leq 0,05)$ nos períodos de 8 a 35 dias em relação aos frangos que receberam o regime de alimentação à vontade, sem diferir dos frangos mantidos sob restrição alimentar de 2 horas à tarde $(\mathrm{P}>0,05)$ e, de 8 a 42 dias o ganho de peso dos frangos submetidos da restrição alimentar de 4 horas $(\mathrm{MT})$ foi maior $(\mathrm{P}=0317)$ em relação aos frangos que receberam o regime de alimentação à vontade, sem diferir dos frangos mantidos nos outros métodos de restrição alimentar $(\mathrm{P}>0,05)$. A restrição alimentar de curta duração nos períodos de manhã e tarde avaliada neste trabalho parece estimular mais o ganho de peso dos frangos que o tradicional consumo ad libitum. Este resultado corrobora estudos anteriores (Demir et al., 2004, Butzen et al., 2013 e Rahimi et al., 2015) que avaliaram restrições alimentar por períodos mais longos de tempo. Entretanto, Saleh et al. (2005) e Mohebodini et al. (2009) não constataram recuperação no peso dos frangos submetidos a diferentes tipos de restrição alimentar.

A conversão alimentar dos frangos do tratamento ad libitum foi semelhante àquelas dos frangos recebendo os programas de restrição alimentar. Semelhantes resultados foram descritos por Novel et al. (2009), Sahraei \& Hadloo (2012) e Mirshamsollahi (2013), enquanto, Saleh et al. (2005) e Jalal \& Zakaria (2012) encontraram melhor conversão alimentar para os frangos mantidos sob restrição alimentar.

Apesar da conversão alimentar não haver diferença entre os tratamentos, os frangos sob restrição ao tempo de oferta de ração de 4 e 2 horas pela tarde ou manhã apresentaram eficiência de aproximadamente 1,5; 1,2 e 0,9\% melhor que os animais 
com alimentação ad libitium. Segundo Furlan et al. (2002), a disponibilidade de nutrientes favorece o desenvolvimento das funções secretoras e absortivas do trato gastrintestinal, contribuindo para o melhor aproveitamento dos nutrientes. Sugerindo que os frangos podem ter apresentado uma adaptação ao tempo de restrição da ração, forçando o aumento do consumo de ração (1,32 e $0,94 \%$ ) minutos antes da suspensão da oferta de ração (Tabela 2).

Segundo Yu \& Robinson (1992), frangos com menor peso corporal apresentam exigências de manutenção reduzidas e podem direcionar mais nutrientes para o crescimento no período de alimentação ad libitum subsequente, resultando em uma diminuição da conversão alimentar. Além disso, Romero et al. (2009) mostraram que a ingestão reduzida de ração resulta em energia reduzida alocada à manutenção, provavelmente por causa da termogênese induzida pela dieta reduzida.

\section{Índice de glicose}

As concentrações de glicose em frangos aos 42 dias de idade foram afetadas $(p \leq 0,001)$ pelos programas de alimentação (Figura 1) e os períodos de coleta (Figura 2).

O nível de glicose foi superior para os frangos que receberam ração à vontade comparado aos frangos sob restrição alimentar de 4 h diária ( 2 h de manhã e 2 h tarde). Resultado contrário foi observado por Mohebodini et al. (2009), que não encontraram variação da concentração de glicose em frangos sob restrição alimentar e alimentação ad libitum.

Os frangos do programa de restrição alimentar $2 \mathrm{~h}$ a tarde (RT) apresentaram concentração de glicose inferior $(\mathbf{p} \leq 0,0001)$ aos frangos dos outros programas de restrição alimentar.

Figura 1. Níveis de glicose de frangos alimentados com diferentes programas de alimentação ${ }^{1}$.

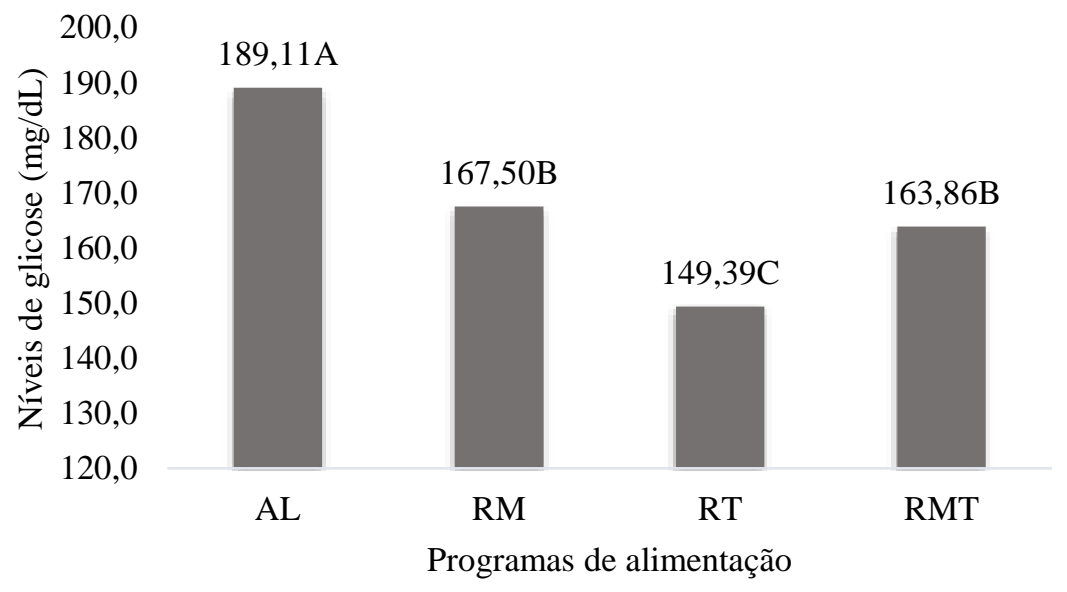

\footnotetext{
${ }^{\mathrm{A}, \mathrm{B}}$ Médias seguidas de letras maiúsculas distintas diferem entre si pelo teste de Tukey $(\mathrm{P}>0,05)$;

Valor de $\mathrm{P}=<0,0001 ; \mathrm{EPM}=2,04 ; \mathrm{CV}(\%)=8,23$.

${ }^{1}$ Programa $1\left(\mathrm{P}_{1}\right)$ : Alimentação ad libitum durante todo o período experimental (AL); $\mathrm{P}_{2}$ : Suspenção da oferta de ração nos intervalos de 06:00 às 08:00 h da manhã (RM); $\mathrm{P}_{3}$ : Suspenção da oferta de ração nos intervalos de 13:00 às 15:00 h da tarde (RT) e; $\mathrm{P}_{4}$ : Suspenção da oferta de ração nos intervalos de 06:00 às 08:00 h da manhã e de 13:00 às 15:00 h da tarde (RMT);

Fonte: Elaborada pelos autores.
}

Houve aumento $(\mathrm{p} \leq 0,0001)$ dos níveis de glicose no sangue após o jejum comparado com a coleta antes e durante a restrição alimentar, mostrando que a restrição continua de ração é condição indispensável à manutenção dos níveis de glicemia sérica de glicose em frangos (Figura 2). Este resultado concorda com o obtido por Zhan et al. (2007). Ao contrário, Rajman et al. (2006), Chen et al. (2012) e Shabani et al. (2015) relataram que os frangos mantem o nível de glicose estável durante o jejum. 
Figura 2. Níveis de glicose em função ao período de coleta dos frangos sob restrição alimentar.

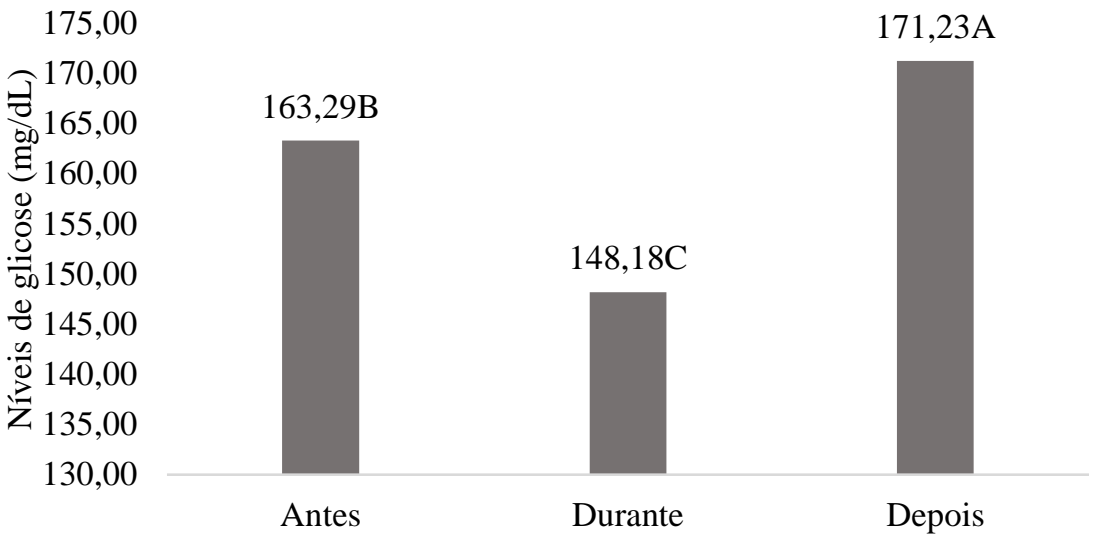

Período de coleta

\footnotetext{
${ }^{\mathrm{A}, \mathrm{B}}$ Médias seguidas de letras maiúsculas distintas diferem entre si pelo teste de Tukey $(\mathrm{P}>0,05)$; Valor de $\mathrm{P}=<0,001 ; \mathrm{EPM}=2,04 ; \mathrm{CV}(\%)=8,23$.

Fonte: Elaborada pelos autores.
}

Durante o jejum, os níveis séricos de glicose declinaram por que a mesma é utilizada pelas células como fonte de energia e seu aporte intestinal está reduzido (Dalla Costa et al., 2008). Num primeiro momento, no intuito de tentar manter estáveis os níveis séricos de glicose, o pâncreas estimula a liberação do hormônio glucagon que promove a quebra do glicogênio hepático, elevando assim os níveis séricos de glicose (Bertol et al., 2005), mas como a reserva de glicogênio hepático é limitada e exaurese rapidamente os níveis séricos de glicose logo declinam.

\section{Rendimento de carcaça e cortes nobres e peso da gordura}

Os rendimentos de carcaça e cortes nobres dos frangos de corte aos 42 dias de idade não apresentaram diferenças dos programas de alimentação $(\mathrm{P}>0,05)$. Por outro lado, os pesos da gordura abdominal foram influenciados $(\mathrm{p} \leq 0,05)$ pelos programas de alimentação (Tabela 3).

Os resultados de rendimento de carcaça e dos cortes nobres mostraram que os programas de restrição alimentar não afetam os componentes da carcaça de frangos. Os resultados deste trabalho parecem indicar que a restrição alimentar de curta duração melhora o desempenho dos frangos mais pela melhoria da eficiência alimentar e menos pelo ganho compensatório, o que é diferente das restrições alimentares de longo prazo o que por ser mais severas que tendem a estimular o ganho compensatório dos frangos (Teimouri et al., 2005; Zhan et al., 2007; Tesfaye et al., 2011; Jalal \& Zakaria, 2012 e Bortoluzzi et al., 2013). Ocak \& Sivri (2008) relataram que durante o período de realimentação os componentes da carcaça respondem mais rapidamente a realimentação do que o corpo inteiro.

O peso da gordura abdominal do grupo de frangos alimentados ad libitum foi maior $(\mathrm{p} \leq 0,05)$ em comparação com os frangos submetidos ao jejum de 2 h, independentemente, do turno que a suspenção da oferta de ração foi aplicada. Estes resultados concordam com aqueles de Cornejo et al. (2007), Yang et al. (2009), Jalal \& Zakaria (2012) e Mirshamsollahi (2013). Este fato pode ser explicado pelo aumento de genes acetil-CoA carboxilase (ACC), ácido graxo sintase (FAZ), estearoil-CoA dessaturase-1 (SCD1) e proteína ligadora de ácidos graxos (FABP) nos fígados de frangos com alimentação ad libitum em comparação a restrição alimentar (Richards et al., 2003). Como o principal modo de regulação da lipogênese hepática pelo estado nutricional é ao nível da transcrição gênica (Hillgartner et al., 1995), isso poderia sinalizar uma maior taxa de lipogênese nas aves ad libitum neste momento (Richards et al., 2003). 
Tabela 3. Efeito de diferentes programas de alimentação sobre o rendimento de carcaça e cortes nobres e do peso de gordura e penas de frangos de corte aos 42 dias

\begin{tabular}{|c|c|c|c|c|c|c|c|}
\hline \multirow{3}{*}{ Parâmetros } & \multicolumn{4}{|c|}{ Programas de alimentação ${ }^{1}$} & \multirow{3}{*}{ EPM } & \multirow{3}{*}{ Valor de $\mathrm{P}$} & \multirow{3}{*}{$\mathrm{CV}(\%)$} \\
\hline & \multirow{2}{*}{ Ad libitum } & \multicolumn{3}{|c|}{ Tempo de restrição à ração } & & & \\
\hline & & $2 \mathrm{~h}(\mathrm{M})$ & $2 \mathrm{~h}(\mathrm{~T})$ & $4 \mathrm{~h}(\mathrm{MT})$ & & & \\
\hline Carcaça (\%) & $82,50 \pm 2,4$ & $82,15 \pm 1,9$ & $83,67 \pm 1,3$ & $84,25 \pm 1,8$ & 0,34 & 0,1699 & 2,25 \\
\hline Peito $(\%)$ & $38,21 \pm 2,0$ & $38,80 \pm 3,2$ & $37,10 \pm 2,1$ & $38,78 \pm 0,6$ & 0,37 & 0,8731 & 5,63 \\
\hline $\operatorname{Coxa}(\%)$ & $11,03 \pm 0,4$ & $11,60 \pm 0,6$ & $11,41 \pm 0,7$ & $10,89 \pm 0,5$ & 0,11 & 0,0552 & 4,93 \\
\hline Sobrecoxa $(\%)$ & $12,07 \pm 0,4$ & $12,63 \pm 0,9^{a}$ & $12,59 \pm 0,7$ & $13,01 \pm 0,8$ & 0,14 & 0,1054 & 5,83 \\
\hline Asa $(\%)$ & $9,06 \pm 0,6$ & $9,08 \pm 0,6$ & $8,92 \pm 0,5$ & $9,66 \pm 0,9$ & 0,12 & 0,1515 & 7,28 \\
\hline Gordura $(\mathrm{g})^{*}$ & $38,67 \pm 4,8^{\mathrm{A}}$ & $32,50 \pm 4,8^{\mathrm{B}}$ & $33,00 \pm 3,3^{\mathrm{B}}$ & $35,83 \pm 3,7^{\mathrm{AB}}$ & 0,83 & 0,0486 & 6,00 \\
\hline
\end{tabular}

A,B Médias seguidas de letras maiúsculas na coluna diferem entre si pelo teste de Duncan $(\mathrm{P}>0,05)$;

${ }^{1}$ Programa $1\left(\mathrm{P}_{1}\right)$ : Alimentação ad libitum durante todo o período experimental (AL); $\mathrm{P}_{2}$ : Suspenção da oferta de ração nos intervalos de 06:00 às 08:00 h da manhã (RM); $P_{3}$ : Suspenção da oferta de ração nos intervalos de 13:00 às 15:00 h da tarde (RT) e; P4: Suspenção da oferta de ração nos intervalos de 06:00 às 08:00 h da manhã e de 13:00 às 15:00 h da tarde (RMT);

*Dados transformados $\left(\mathrm{x}^{0,5}\right) ; \mathrm{EPM}=$ erro-padrão da média; $\mathrm{CV}=$ coeficiente de variação.

Fonte: Elaborada pelos autores.

Por outro lado, Rosebrough et al. (1986) as atividades das enzimas lipogênicas ficam deprimidas durante o período de restrição alimentar e atingem o pico de atividade na primeira semana de realimentação, diminuindo gradualmente para níveis inferiores em relação as aves de oferta de ração ad libitum nas semanas subsequentes. Desta forma, os métodos da restrição alimentar tendem a melhorar a qualidade de carcaça com a redução da deposição de gordura (Zhan et al., 2007).

\section{Peso dos órgãos comestiveis}

Os pesos dos órgãos de frangos de corte aos 42 dias de idade não foram afetados $(\mathrm{P}>0,05)$ pelos programas de alimentação (Tabela 4). Resultados semelhantes foram colhidos por Novel et al. (2009) e Hassanien (2011), que não observaram diferenças significativas no peso do coração e fígado entre os grupos de frangos submetidos a restrição alimentar comparado aos frangos de alimentação ad libitum de ração. Ao contrário, Tesfaye et al. (2011) e Jalal \& Zakaria (2012), observaram diferenças no peso do fígado entre aves com restrição alimentar e aves do tratamento ad libitum.

Van der Klein et al. (2017), avaliando o efeito da restrição alimentar durante a segunda (90, 80 e $70 \%$ do alimento ad libitum) e terceira (90, 85 e $80 \%$ do alimento ad libitum) semanas de idade em frangos do sexo misto também não verificaram diferença significativa dos tratamentos de restrição alimentar no musculo do peito, gordura abdominal, coração, pernas e fígado aos 35 dias de idade.

Tabela 4. Efeito de diferentes programas de alimentação sobre peso dos órgãos comestíveis de frangos de corte aos 42 dias

\begin{tabular}{lccc}
\hline \hline Programas de alimentação $^{1}$ & Coração $(\mathrm{g})$ & Moela $(\mathrm{g})$ & Fígado $\mathrm{g})$ \\
\hline 1 - Ad libitum $_{2}$ & $11,13 \pm 1,0$ & $38,50 \pm 4,7$ & $40,00 \pm 2,3$ \\
- Restrição de 2 h (M) & $10,00 \pm 0,8$ & $40,25 \pm 5,9$ & $40,13 \pm 5,3$ \\
3 - Restrição de 2 h (T) & $11,75 \pm 2,2$ & $42,69 \pm 3,2$ & $37,25 \pm 3,0$ \\
4 - Restrição de 4 h (MT) & $10,88 \pm 1,4$ & $42,63 \pm 3,9$ & $38,25 \pm 2,9$ \\
EPM & 0,3 & 0,8 & 0,6 \\
\hline Valor de P & 0,1285 & 0,2123 & 0,3202 \\
\hline CV $(\%)$ & 13,07 & 11,14 & 9,19 \\
\hline
\end{tabular}

A,B Médias seguidas de letras maiúsculas na coluna diferem entre si pelo teste de Duncan $(\mathrm{P}>0,05)$;

${ }^{1}$ Programa $1\left(\mathrm{P}_{1}\right)$ : Alimentação ad libitum durante todo o período experimental (AL); $\mathrm{P}_{2}$ : Suspenção da oferta de ração nos intervalos de 06:00 às 08:00 h da manhã $(\mathrm{RM}) ; \mathrm{P}_{3}$ : Suspenção da oferta de ração nos intervalos de 13:00 às 15:00 h da tarde (RT) e; $\mathrm{P}_{4}$ : Suspenção da oferta de ração nos intervalos de 06:00 às 08:00 h da manhã e de 13:00 às 15:00 h da tarde (RMT);

$\mathrm{EPM}=$ erro-padrão da média; $\mathrm{CV}=$ coeficiente de variação.

Fonte: Elaborada pelo autor. 


\section{Medidas físicas do osso do fêmur e tíbia de frangos}

Não houve $(P>0,05)$ efeito dos programas de alimentação nos parâmetros físicos do osso do fêmur e tíbia de frangos de corte aos 42 dias de idade (Tabela 5).

Estes resultados confirmam que os métodos de restrição alimentar não afetaram o crescimento e a mineralização normal do fêmur e tíbia dos frangos. Pelicano et al. (2005) não verificaram diferenças estatísticas no diâmetro e comprimento do fêmur em frangos no período final (29 a 42 dias) com a restrição energética e proteica. Contrariando este resultado, Van Wyhe et al. (2014) observaram o fêmur de perus sob restrição alimentar de 60\% da proteína e da energia ficou mais compridos comparado ao grupo de perus que receberam alimentação ad libitum. Bruno et al. (2000) relataram que a restrição alimentar qualitativa reduziu o crescimento e a largura dos ossos longos dos frangos, sem afetar o seu peso.

Tabela 5. Efeito de diferentes programas de alimentação sobre as medidas físicas do osso de frangos de corte aos 42 dias

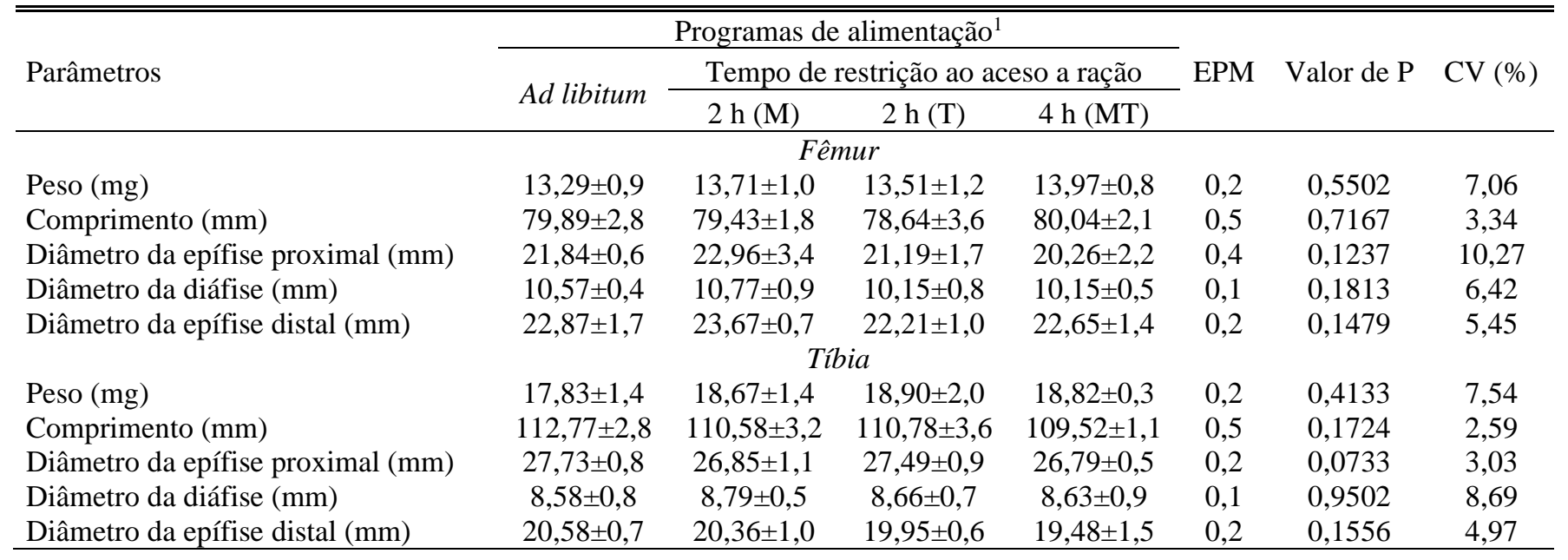

a,b Médias seguidas de letras minúsculas na linha diferem entre si pelo teste de Duncan $(\mathrm{P}>0,05)$.

${ }^{1}$ Programa $1\left(\mathrm{P}_{1}\right)$ : Alimentação ad libitum durante todo o período experimental (AL); $\mathrm{P}_{2}$ : Suspenção da oferta de ração nos intervalos de 06:00 às 08:00 h da manhã $(\mathrm{RM}) ; \mathrm{P}_{3}$ : Suspenção da oferta de ração nos intervalos de 13:00 às 15:00 h da tarde (RT) e; $\mathrm{P}_{4}$ : Suspenção da oferta de ração nos intervalos de 06:00 às 08:00 h da manhã e de 13:00 às 15:00 h da tarde (RMT);

$\mathrm{EPM}=$ erro-padrão da média; $\mathrm{CV}=$ coeficiente de variação.

Fonte: Elaborada pelo autor.

De forma geral, o método de restrição alimentar empregado no presente estudo, provam que o período do dia e o curto tempo de duração da restrição alimentar não provocam desnutrição nos frangos, considerando que a desnutrição afetaria o crescimento e a mineralização óssea. Segundo Bonjour (2005), a privação de alimento no período pós-natal pode comprometer permanentemente a estrutura esquelética. Entretanto, alguns autores relatam que a restrição alimentar (Even-Zohar et al., 2008) em período curto de jejum (Heinrichs et al., 1997; Farnum et al., 2003) em animais jovens ocasiona danos sobre a morfologia da placa epifisária e comprometem o crescimento ósseo longitudinal (Heinrichs et al., 1997; Farnum et al., 2003; Even-Zohar et al., 2008).

\section{Medidas biomecânicas do osso do fêmur e tíbia de frangos}

Os programas de alimentação não afetaram o índice Seedor do fêmur e resistência à quebra do fêmur e da tíbia ( $\mathrm{P}>0,05)$. Por outro lado, o índice de Seedor da tíbia foram afetados $(\mathrm{p} \leq 0,05)$ pelos os programas de restrição alimentar em frangos de corte aos 42 dias de idade (Tabela 6). 
Tabela 6. Efeito de diferentes programas de alimentação sobre as medidas biomecânicas2 dos fêmures e tíbias de frangos de corte aos 42 dias

\begin{tabular}{|c|c|c|c|c|}
\hline \multirow{2}{*}{ Programa de alimentaçãó ${ }^{1}$} & \multicolumn{2}{|c|}{ Fêmur } & \multicolumn{2}{|c|}{ Tíbia } \\
\hline & IS (mg/mm) & $\mathrm{RO}\left(\mathrm{kgf} / \mathrm{cm}^{2}\right)$ & $\mathrm{IS}(\mathrm{mg} / \mathrm{mm})$ & $\mathrm{RO}\left(\mathrm{kgf} / \mathrm{cm}^{2}\right)$ \\
\hline 1 - Ad libitum & $0,166 \pm 0,01$ & $35,08 \pm 0,93$ & $0,158 \pm 0,01^{\mathrm{B}}$ & $42,64 \pm 2,99$ \\
\hline 2 - Restrição de 2 h (M) & $0,173 \pm 0,01$ & $24,88 \pm 0,84$ & $0,169 \pm 0,01^{\mathrm{AB}}$ & $42,85 \pm 1,95$ \\
\hline 3 - Restrição de 2 h (T) & $0,172 \pm 0,01$ & $32,42 \pm 1,43$ & $0,170 \pm 0,01^{\mathrm{A}}$ & $43,50 \pm 6,83$ \\
\hline 4 - Restrição de 4 h (MT) & $0,175 \pm 0,01$ & $36,26 \pm 2,01$ & $0,172 \pm 0,01^{\mathrm{A}}$ & $43,86 \pm 5,87$ \\
\hline EPM & 0,002 & 0,83 & 0,002 & 0,82 \\
\hline Valor de $\mathrm{P}$ & 0,3674 & 0,4260 & 0,0269 & 0,4260 \\
\hline $\mathrm{CV}(\%)$ & 5,70 & 4,44 & 3,59 & 4,44 \\
\hline
\end{tabular}

${ }^{\mathrm{A}, \mathrm{B}}$ Médias seguidas de letras maiúsculas na coluna diferem entre si pelo teste de Duncan $(\mathrm{P}>0,05)$.

${ }^{1}$ Programa $1\left(\mathrm{P}_{1}\right)$ : Alimentação ad libitum durante todo o período experimental (AL); $\mathrm{P}_{2}$ : Suspenção da oferta de ração nos intervalos de 06:00 às 08:00 h da manhã $(\mathrm{RM}) ; \mathrm{P}_{3}$ : Suspenção da oferta de ração nos intervalos de 13:00 às 15:00 h da tarde (RT) e; $\mathrm{P}_{4}$ : Suspenção da oferta de ração nos intervalos de 06:00 às 08:00 h da manhã e de 13:00 às 15:00 h da tarde (RMT);

${ }^{2} \mathrm{IS}=$ índice de Seedor, RO = resistência óssea; $\mathrm{EPM}=$ erro-padrão da média; CV = coeficiente de variação.

Fonte: Elaborada pelo autor.

A restrição alimentar não afetou $(\mathrm{P}>0,05)$ a resistência à quebra dos ossos dos frangos. Discordando dos resultados de Bruno et al. (2000) que verificaram maior resistência óssea nos animais submetidos a restrição alimentar quantitativa em diferentes temperaturas.

Resultados de trabalhos com restrição alimentar com ratos mostraram que a restrição alimentar causou uma baixa resistência óssea e menor comprimento dos ossos curtos acompanhado do decréscimo na velocidade de formação óssea, aumento da reabsorção e diminuição do volume do tecido osso trabecular durante o crescimento rápido do esqueleto (Devlin et al., 2010).

O índice Seedor da tíbia de frangos alimentados com os programas de restrição alimentar por $4 \mathrm{~h}$ (manhã e tarde) e de $2 \mathrm{~h}$ à tarde foram maiores $(\mathrm{P}=0,0269)$ em comparação com os frangos com alimentação ad libitum. Segundo Almeida Paz et al. (2009) a resistência à quebra do osso e o índice Seedor estão intimamente relacionados a qualidade e saúde do tecido ósseo. Por outro lado, os frangos submetidos a restrição alimentar de $2 \mathrm{~h}$ à manhã tiveram índice Seedor da tíbia semelhante aos frangos com alimentação ad libitum ( $\mathrm{P}>0,05)$. Discordando com o presente estudo, Bruno et al. (2000) observaram índice, sendo mais baixo para frangos de corte em restrição alimentar.

\section{Avaliação econômica dos programas alimentares}

Os programas de restrição alimentar não influenciaram os resultados na análise econômica do percentual de mortalidade (P>0,05) em comparação com o tratamento ad libitum (Tabela 7).

Tabela 7. Valores econômicos ${ }^{2}$ na produção de frangos alimentados com diferentes programas de alimentação

\begin{tabular}{|c|c|c|c|c|c|c|c|c|}
\hline $\begin{array}{l}\text { Programas de } \\
\text { alimentação }^{1}\end{array}$ & RBM (R\$/ave) & CMA (R\$/ave) & MBM & $\mathrm{RM}$ & IRR & VIAB (\%) & IEP & MO* (\%) \\
\hline 1 - Ad libitum & 11,10 & 6,24 & 4,86 & 77,86 & 100,00 & 99,89 & 428,23 & 0,11 \\
\hline $2-2 \mathrm{~h}(\mathrm{M})$ & 11,10 & 6,30 & 4,80 & 76,16 & 98,02 & 100,00 & 432,58 & 0,00 \\
\hline $3-2 h(T)$ & 11,07 & 6,21 & 4,87 & 78,47 & 100,00 & 99,67 & 431,68 & 0,33 \\
\hline $4-4 \mathrm{~h}(\mathrm{RMT})$ & 11,17 & 6,33 & 4,85 & 76,57 & 98,50 & 99,78 & 436,79 & 0,22 \\
\hline Valor de $\mathrm{P}$ & 0,9161 & 0,1251 & 0,9379 & 0,5720 & 0,7045 & 0,8251 & 0,2808 & 0,2808 \\
\hline $\mathrm{CV}(\%)$ & 2,71 & 1,81 & 5,22 & 5,10 & -- & 3,25 & 0,36 & \\
\hline
\end{tabular}

A,B Médias seguidas de letras maiúsculas na coluna diferem entre si pelo teste de Duncan $(\mathrm{P}>0,05)$;

${ }^{1}$ Programa $1\left(\mathrm{P}_{1}\right)$ : Alimentação ad libitum durante todo o período experimental (AL); $\mathrm{P}_{2}$ : Suspenção da oferta de ração nos intervalos de 06:00 às 08:00 h da manhã $(\mathrm{RM}) ; \mathrm{P}_{3}$ : Suspenção da oferta de ração nos intervalos de 13:00 às 15:00 h da tarde (RT) e; $\mathrm{P}_{4}$ : Suspenção da oferta de ração nos intervalos de 06:00 às 08:00 h da manhã e de 13:00 às 15:00 h da tarde (RMT); 
${ }^{2}$ Renda bruta média (RBM), custo médio de arraçoamento (CMA), margem bruta média (MBM), rentabilidade média (RM), índice relativo de rentabilidade (IRR), viabilidade (VIAB), índice de eficiência produtiva (IEP) e mortalidade (MO);

$\mathrm{EPM}=$ erro-padrão da média; $\mathrm{CV}=$ coeficiente de variação; ${ }^{*}$ Dados transformados: $(\mathrm{X}+0,05)^{0,5}$.

Fonte: Elaborada pelo autor.

Apesar dos programas de restrição alimentar não afetarem o desempenho econômico do lote $(\mathrm{P}>0,05)$, ocorreu a tendência de maior eficiência produtiva $(436,79$ vs 430,66) para as aves que foram submetidos a restrição alimentar de 4 horas pela manhã e tarde comparado aos frangos que foram alimentadas ad libitum.

Os índices econômicos não foram influenciados pelos programas de alimentação. Ramos et al. (2011) também não observaram diferenças estatísticas nos índices econômicos de custo médio de arroçoamento, margem bruta média, rentabilidade média e índice relativo de rentabilidade de frangos de corte submetidas a restrição alimentar em relação ao ad libitum. Entretanto, Novel et al. (2009), Hassanien (2011) e Tesfaye et al. (2011) observaram vantagem econômica para o grupo de frangos tratados com restrição alimentar em comparação com o grupo de alimentação ad libitum.

Os programas de restrição alimentar não afetaram a mortalidade, concordando com os relatos de Demir et al. (2004), Oyedeji \& Atteh (2005), Novel et al. (2009) e Butzen et al. (2013), mas, alguns pesquisadores conseguiram reduzir a mortalidade aplicando métodos de restrição alimentar para frangos de corte (Saleh et al., 2005; Teimouri et al., 2005; Özkan et al., 2010).

\section{Conclusão}

O programa restrição alimentar quantitativo de 4 horas ( 2 horas pela manhã e 2 horas à tarde) melhora o desempenho, qualidade óssea e econômica nos frangos de corte de 8 aos 42 dias de idade.

\section{Agradecimentos}

Os autores agradecem à Coordenação de Aperfeiçoamento de Pessoal de Nível Superior (CAPES) pela concessão da bolsa.

\section{Referências}

Almeida Paz, I. C. L., Mendes, A. A., Balog, A., Komiyama, C. M., Takahashi, S. E., Almeida, I. C. L., ... \& Cardoso, K. F. G. (2009). Efeito do cálcio na qualidade óssea e de ovos de poedeiras. Archivos de Zootecnia, 58(222), 173-183.

Araújo, G. M., Vieites, F. M., Barbosa, A. A., Caramori Junior, J. G., Santos, A. L., Moraes, G. H. K., ... \& Muller, E. S. (2011). Variação aniônica da dieta sobre características ósseas de frangos de corte: resistência à quebra, composição orgânica e mineral. Arquivo Brasileiro de Medicina Veterinária e Zootecnia, $63,954-961$.

Bartlett, M. S. (1947). The use of transformations. Biometrics, 3(1), 39-52.

Bertol, T. M., Ellis, M., Hamilton, D. N., Johnson, E. W., \& Ritter, M. J. (2005). Effects of dietary supplementation with L-carnitine and fat on blood acid-base responses to handling in slaughter weight pigs. Journal of Animal Science, 83(1), 75-81.

Bonjour, J. P. (2005). Dietary protein: an essential nutrient for bone health. Journal of the American College of Nutrition, 24(sup6), 526S-536S.

Bortoluzzi, C., Fernandes, J. I. M., Contini, J. P., Gurski, T. J., Esser, A. F. G., \& Prokoski, K. (2013). Quantitative feed restriction from 35 to 42 days of age for broiler chickens. Revista Brasileira de Saúde e Produção Animal, 14, 778-784.

Bruno, L. D. G., Furlan, R. L., Malheiros, E. B., \& Macari, M. (2000). Influence of early quantitative food restriction on long bone growth at different environmental temperatures in broiler chickens. British Poultry Science, 41(4), 389-394.

Butzen, F. M., Ribeiro, A. M. L., Vieira, M. M., Kessler, A. M., Dadalt, J. C., \& Della, M. P. (2013). Early feed restriction in broilers. I-Performance, body fraction weights, and meat quality. Journal of Applied Poultry Research, 22(2), 251-259.

Chen, W., Guo, Y. M., Huang, Y. Q., Shi, Y. H., Zhang, C. X., \& Wang, J. W. (2012). Effect of Energy Restriction on Growth, Slaughter Performance, Serum Biochemical Parameters and Lpin2/WDTC1/mRNA Expressionof Broilers in the Later Phase. The Journal of Poultry Science, 49(1), 12-19.

Cornejo, S., Gadelha, A. C., Pokniak, J., \& Villouta, G. (2007). Qualitative feed restriction on productive performance and lipid metabolism in broiler chickens. Arquivo Brasileiro de Medicina Veterinária e Zootecnia, 59, 1554-1562. 
Research, Society and Development, v. 10, n. 12, e04101219823, 2021

(CC BY 4.0) | ISSN 2525-3409 | DOI: http://dx.doi.org/10.33448/rsd-v10i12.19823

Dalla Costa, O. A., Ludke, J. V., Costa, M. J. R. P. D., Faucitano, L., Coldebella, A., Kich, J. D., ... \& Dalla Roza, D. (2008). Tempo de jejum na granja sobre o perfil hormonal e os parâmetros fisiológicos em suínos de abate pesados. Ciência Rural, 38, 2300-2306.

Demir, E., Sarica, S., Sekeroglu, A., Ozcan, M. A., \& Seker, Y. (2004). Effects of early and late feed restriction or feed withdrawal on growth performance, ascites and blood constituents of broiler chickens. Acta Agriculturae Scandinavica, Section A-Animal Science, 54(3), 152-158.

Devlin, M. J., Cloutier, A. M., Thomas, N. A., Panus, D. A., Lotinun, S., Pinz, I., ... \& Bouxsein, M. L. (2010). Caloric restriction leads to high marrow adiposity and low bone mass in growing mice. Journal of Bone and Mineral Research, 25(9), 2078-2088.

Duarte, K. F., Junqueira, O. M., Borges, L. L., Santos, E. T., Marques, R. H., de Quadros, T. C. O., \& Domingues, C. H. D. F. (2012). Desempenho e morfometria duodenal de frangos de corte submetidos a diferentes níveis de energia e programas de alimentação de 42 a 57 dias de idade. Ciência Animal Brasileira, 13(2), 197-204.

Even-Zohar, N., Jacob, J., Amariglio, N., Rechavi, G., Potievsky, O., Phillip, M., \& Gat-Yablonski, G. (2008). Nutrition-induced catch-up growth increases hypoxia inducible factor $1 \alpha$ RNA levels in the growth plate. Bone, 42(3), 505-515.

Farnum, C. E., Lee, A. O., O'Hara, K., \& Wilsman, N. J. (2003). Effect of short-term fasting on bone elongation rates: an analysis of catch-up growth in young male rats. Pediatric Research, 53(1), 33-41.

Furlan, R. L., Machado, J. G. D. C. F., Giachetto, P. F., Malheiros, E. B., Furlan, L. R., \& Macari, M. (2002). Desempenho e composição da carcaça de frangos de corte submetidos a diferentes períodos de arraçoamento. Revista Brasileira de Zootecnia, 31, 2265-2273.

Gomes, P. C., Albino, L. F. T., \& Silva, M. D. (1996). Criação de frangos de corte (Vol. 17, p. 18). Viçosa - MG MG: UFV.

Guyton, A., \& Hall, J. E. (1997). Tratado de Fisiologia Médica (9º Edição). Ed. Guanabara Koogan: Rio de Janeiro.

Hassanien, H. H. M. (2011). Productive performance of broiler chickens as affected by feed restriction systems. Asian Journal of Poultry Science, 5(1), 21-27.

Heinrichs, C., Colli, M., Yanovski, J. A., Laue, L., Gerstl, N. A., Kramer, A. D., ... \& Baron, J. (1997). Effects of fasting on the growth plate: systemic and local mechanisms. Endocrinology, 138(12), 5359-5365.

Hillgartner, F. B., Salati, L. M., \& Goodridge, A. G. (1995). Physiological and molecular mechanisms involved in nutritional regulation of fatty acid synthesis. Physiological reviews, 75(1), 47-76.

Jalal, M. A., \& Zakaria, H. A. (2012). The effect of quantitative feed restriction during the starter period on compensatory growth and carcass characteristics of broiler chickens. Pakistan Journal of Nutrition, 11(9), 719.

Saber, S. N., Maheri-Sis, N., Shaddel-Telli, A., Hatefinezhad, K., Gorbani, A., \& Yousefi, J. (2011). Effect of feed restriction on growth performance of broiler chickens. Annals of Biological Research, 2(6), 247-252.

Mirshamsollahi, A. (2013). Effect of different food restriction on performance and carcass characteristics of Arian and Ross broiler chicks. International Journal of Agriculture, 3(3), 495.

Mohebodini, H., Dastar, B., Sharg, M. S., \& Zerehdaran, S. (2009). The Comparison of Early Feed Restriction and Meal Feeding. Journal of Animal and Veterinary Advances, 8(10), 2069-2074.

Novel, D. J., Ng'Ambi, J. W., Norris, D., \& Mbajiorgu, C. A. (2009). Effect of different feed restriction regimes during the starter stage on productivity and carcass characteristics of male and female Ross 308 broiler chickens. Int. J. Poult. Sci, 8(1), 35-39.

Ocak, N., \& Sivri, F. (2008). Liver colourations as well as performance and digestive tract characteristics of broilers may change as influenced by stage and schedule of feed restriction. Journal of Animal Physiology and Animal Nutrition, 92(5), 546-553.

Oyedeji, J. O., \& Atteh, J. O. (2005). Response of broilers to feeding manipulations. International Journal of Poultry Science, 4(2), 91-95.

Özkan, S. E. Z. E. N., Takma, C. İ. Ğ. D. E. M., Yahav, S., Söğüt, B., Türkmut, L., Erturun, H., \& Cahaner, A. (2010). The effects of feed restriction and ambient temperature on growth and ascites mortality of broilers reared at high altitude. Poultry Science, 89(5), 974-985.

Park, S. Y., Birkhold, S. G., Kubena, L. F., Nisbet, D. J., \& Ricke, S. C. (2003). Effect of storage condition on bone breaking strength and bone ash in laying hens at different stages in production cycles. Poultry Science, 82(11), 1688-1691.

Pelicano, E. R. L., Bernal, F. E. M., Furlan, R. L., Malheiros, E. B., \& Macari, M. (2005). Efeito da temperatura ambiente e da restrição alimentar protéica ou energética sobre o ganho de peso e crescimento ósseo de frangos de corte. Arquivo Brasileiro de Medicina Veterinária e Zootecnia, 57, 353-360.

Ramos, K. C. B. T., da Costa Gomes, A. V., de Lima, C. A. R., Camargo, A. M., Curvello, F. A., Silva, R. V. M. M., \& de Andrade Massi, P. (2011). Desempenho produtivo e econômico de frangos de corte submetidos a programas de restrição alimentar. Ciência Animal Brasileira, 12(1), 08-16.

Rahimi, S., Seidavi, A., Sahraei, M., Blanco, F. P., Schiavone, A., \& Martínez Marín, A. L. (2015). Effects of feed restriction and diet nutrient density during re-alimentation on growth performance, carcass traits, organ weight, blood parameters and the immune response of broilers. Italian Journal of Animal Science, 14(3), 4037.

Rajman, M., Juráni, M., Lamošová, D., Máčajová, M., Sedlačková, M., Košt’ál, L., ... \& Výboh, P. (2006). The effects of feed restriction on plasma biochemistry in growing meat type chickens (Gallus gallus). Comparative Biochemistry and Physiology Part A: Molecular \& Integrative Physiology, 145(3), 363-371.

Religious, K. B., Tesseraud, S., \& Piccady, O. A. (2001). Food neonatale and early development of table fowl. 2001, INRA. Production. Anim, $14,219$. 
Research, Society and Development, v. 10, n. 12, e04101219823, 2021

(CC BY 4.0) | ISSN 2525-3409 | DOI: http://dx.doi.org/10.33448/rsd-v10i12.19823

Richards, M. P., Poch, S. M., Coon, C. N., Rosebrough, R. W., Ashwell, C. M., \& McMurtry, J. P. (2003). Feed restriction significantly alters lipogenic gene expression in broiler breeder chickens. The Journal of Nutrition, 133(3), 707-715.

Romero, L. F., Zuidhof, M. J., Renema, R. A., Naeima, A., \& Robinson, F. E. (2009). Characterization of energetic efficiency in adult broiler breeder hens. Poultry Science, 88(1), 227-235.

Rosa, P. S., de Ávila, V. S., \& Jaenisch, F. R. F. (2000). Restrição alimentar em frangos de corte: Como explorar suas potencialidades. Embrapa Suínos e AvesComunicado Técnico (INFOTECA-E).

Rostagno, H. S., Albino, L., Donzele, J. L., Gomes, P. C., De Oliveira, R. F., Lopes, D. C., ... \& Euclides, R. (2011). Tabelas brasileiras para suínos e aves: composição de alimentos e exigências nutricionais (HS Rostagno. In 3rd ed. UFV Viçosa, Minas Gerais, Brasil.

Sahraei, M., \& Hadloo, M. H. M. (2012). Effect of physical feed restriction in finisher period on carcass traits and broiler chickens performance. Global Veterinaria, 9(2), 201-204.

Sahraei, M., \& Sharjatmadarj, F. (2007). Effect of Different Levels of Diet Dilution During Finisher Period. International Journal of Poultry Science, 6(4), 280282.

Saleh, E. A., Watkins, S. E., Waldroup, A. L., \& Waldroup, P. W. (2005). Effects of early quantitative feed restriction on live performance and carcass composition of male broilers grown for further processing. Journal of Applied Poultry Research, 14(1), 87-93.

Seedor, J. G., Quartuccio, H. A., \& Thompson, D. D. (1991). The bisphosphonate alendronate (MK-217) inhibits bone loss due to ovariectomy in rats. Journal of Bone and Mineral Research, 6(4), 339-346.

Shabani, S., Seidavi, A., Asadpour, L., \& Corazzin, M. (2015). Effects of physical form of diet and intensity and duration of feed restriction on the growth performance, blood variables, microbial flora, immunity, and carcass and organ characteristics of broiler chickens. Livestock Science, $180,150-157$.

Sullivan, T. W. (1994). Skeletal problems in poultry: estimated annual cost and descriptions. Poultry Science, 73(6), 879-882.

Teimouri, A., Rezaei, M., Pourreza, J., Sayyahzadeh, H., \& Waldroup, P. W. (2005). Effect of diet dilution in the starter period on performance and carcass characteristics of broiler chicks. Int. J. Poult. Sci, 4(12), 1006-1011.

Tesfaye, E., Tamir, B., Haile, A., \& Dessie, T. (2011). Effect of skip-a-day feed restriction on carcass yield characteristics and economic advantages of Rhode Island Red pullets. African Journal of Agricultural Research, 6(4), 849-855.

Tolkamp, B. J., Sandilands, V., \& Kyriazakis, I. (2005). Effects of qualitative feed restriction during rearing on the performance of broiler breeders during rearing and lay. Poultry Science, 84(8), 1286-1293.

Van der Klein, S. A. S., Silva, F. A., Kwakkel, R. P., \& Zuidhof, M. J. (2017). The effect of quantitative feed restriction on allometric growth in broilers. Poultry Science, 96(1), 118-126.

Van Wyhe, R. C., Regmi, P., Powell, B. J., Haut, R. C., Orth, M. W., \& Karcher, D. M. (2014). Bone characteristics and femoral strength in commercial toms: The effect of protein and energy restriction. Poultry Science, 93(4), 943-952.

Yang, Y. X., Guo, J., Yoon, S. Y., Jin, Z., Choi, J. Y., Piao, X. S., ... \& Chae, B. J. (2009). Early energy and protein reduction: effects on growth, blood profiles and expression of genes related to protein and fat metabolism in broilers. British Poultry Science, 50(2), 218-227.

Yu, M. W., \& Robinson, F. E. (1992). The application of short-term feed restriction to broiler chicken production: a review. Journal of Applied Poultry Research, $1(1), 147-153$.

Zhan, X. A., Wang, M., Ren, H., Zhao, R. Q., Li, J. X., \& Tan, Z. L. (2007). Effect of early feed restriction on metabolic programming and compensatory growth in broiler chickens. Poultry Science, 86(4), 654-660.

Zubair, A. K., \& Leeson, S. (1996). Compensatory growth in the broiler chicken: a review. World's Poultry Science Journal, 52(2), 189-201. 